\title{
Regional Differences in Hourly Precipitation Characteristics along the Western Coast of South China
}

\author{
JIAN LI \\ State Key Laboratory of Severe Weather, Chinese Academy of Meteorological Sciences, China Meteorological Administration, \\ Beijing, China \\ NINA LI \\ Nanjing University of Information Science and Technology, Nanjing, and State Key Laboratory of Severe Weather, \\ Chinese Academy of Meteorological Sciences, China Meteorological Administration, Beijing, China \\ RUCONG YU \\ State Key Laboratory of Severe Weather, Chinese Academy of Meteorological Sciences, China Meteorological Administration, \\ Beijing, China
}

(Manuscript received 13 June 2019, in final form 20 October 2019)

\begin{abstract}
The regional differences in hourly precipitation characteristics along the western coast of South China are investigated. The coastal area can be divided into three regions: two regions with large precipitation amounts to the west and east of the Leizhou Peninsula and another region with less precipitation over the Leizhou Peninsula. The precipitation center west of the Leizhou Peninsula (Dongxing station) is dominated by heavy precipitation, which frequently peaks in the early morning and has a long duration. The precipitation center east of the Leizhou Peninsula (Yangjiang station) has a high frequency of weak precipitation. There are two kinds of precipitation that occur at Yangjiang: short-duration precipitation in the afternoon and long-lasting precipitation in the morning. Over the Leizhou Peninsula (Zhanjiang station), precipitation mainly occurs over a short duration in the afternoon. The possible reasons for the different precipitation features are discussed. The morning precipitation at Dongxing is usually caused by deep convection. A large proportion of the morning precipitation events are locally generated events, which are closely related to the southerly winds and topographic barriers. Among the many possible factors affecting the morning precipitation at Yangjiang, the convergence between the land breeze and prevailing onshore airflow is an important one. The afternoon precipitation events affecting Yangjiang mostly originate over the mountains northwest of Yangjiang. Influenced by the curvature of the coastline and the relatively flat terrain over the Leizhou Peninsula, there is no convergence and less convection in the morning. However, the Leizhou Peninsula is prone to being influenced by daytime thermal forcings, which trigger afternoon precipitation.
\end{abstract}

\section{Introduction}

As one of the maximum rainfall centers in East Asia, the coastal region of South China is frequently influenced by heavy rainfall (Xu et al. 2009), which seriously threatens the safety of inhabitants and property. Considering the urgent need for accurate prediction and disaster prevention, the skills of quantitative precipitation forecasting for intense rainfall are still relatively low at the current stage. Therefore, many efforts have been

Corresponding author: Rucong Yu, yrc@cma.gov.cn made to improve the understanding of precipitation processes over this region. Since 2013, a series of field campaigns have been conducted over southern China as part of the Southern China Monsoon Rainfall Experiment (SCMREX), which provides composite highdensity observations related to various precipitation systems (Luo et al. 2017). The observed regions covered Guangdong, southeastern Guangxi, Hainan, and Hong Kong. The intensive observations, especially those over the enhanced observational area $\left(20^{\circ}-25^{\circ} \mathrm{N}\right.$, $110^{\circ}-117^{\circ} \mathrm{E}$ ), have been widely used to better understand the structures and mechanisms of rainstorms. 
For example, Wang et al. (2014) investigated the convective properties of an extreme rainfall event over the western coast of the Guangdong Province and identified two distinct scales of convective organization. $\mathrm{Wu}$ and Luo (2016) analyzed an extreme rainfall case in 2015 over the eastern coast of the Guangdong Province and found that the cold pools and local terrain can influence the initialization and maintenance of convection.

Many other works have focused on the climatological precipitation characteristics and their variability at various time scales over South China. Xu (2013) found that warm-season precipitation over South China is mainly contributed by large and deep convection systems. Zheng et al. (2016) demonstrated that extreme precipitation events in South China usually have long durations. The extreme events over South China also present an increasing trend over recent decades (Wang and Zhou 2005; Zhao et al. 2014; Wu et al. 2016). Especially for the coastal area of South China, significant increases in extreme precipitation have contributed to the increase in total precipitation for the 1951-2000 period (Zhai et al. 2005). The precipitation also presents significant intraseasonal variations over South China. Luo et al. (2013) noted that the precipitation is influenced by different mechanisms during different monsoonal periods. Chen et al. (2019) found that the boreal summer intraseasonal oscillation is an important factor that induces rainfall subseasonal variation over the coastal area of South China. Based on radar data, Chen et al. (2014) analyzed the spatial and temporal characteristics of convection and found that the highest frequency of convection around the Pearl River delta occurs in June. In addition, there are some works analyzed the features of mesoscale convective systems (MCSs) identified from satellite observations (Ma et al. 1997; Zheng et al. 2008). Zheng and Chen (2013) explored the climatological characteristics of deep convection, and they denoted that the deep convection over the land areas of South China is more active in June while that over the South China Sea is more active in July and August. Yang et al. (2015) revealed that the frequency of MCSs also peaks in June over South China.

As an important aspect of the hourly precipitation characteristics, the diurnal variation in precipitation in South China has also been extensively studied (Yu et al. 2007; Li et al. 2008; Zhou et al. 2008; Chen et al. 2009a,b; Yuan et al. 2012b; Chen et al. 2014; Jiang et al. 2017; Zhu et al. 2017; Li et al. 2018). Yuan et al. (2012a) found that some rain gauge stations along the coastline exhibit early morning peaks in summer. Chen et al. (2014) noted that there are two precipitation peaks over the Pearl River delta region: one peak occurs in the afternoon and the other peak occurs in the early morning. Chen et al. (2013) pointed out that there are many common features between the diurnal variations in warm-season short-duration heavy rainfall and the MCSs. Zheng et al. (2019) noted that the diurnal peak appears between midnight and early morning over the coastal regions of Guangdong, and it is determined by convective activities. Focusing on the regional features of diurnal variations near the coast, Chen et al. (2018) grouped 86 stations in the Guangdong Province into three categories: near coastline, coast-inland transition zone, and inland region. And they found a linear reduction in morning precipitation from the coastal region to the inland region. Du and Rotunno (2018) summarized two propagation modes (onshore and offshore) of the diurnal cycle of precipitation near the coast around the Pearl River delta.

Numerical experiments have also been carried out to simulate the diurnal variations in precipitation over South China and to investigate their corresponding mechanisms. Huang et al. (2013) evaluated the RegCM3 performance in simulating the diurnal variations in rainfall over Southeast China, focusing on the sensitivity of the cumulus parameterization choices. Using the stretched-Nonhydrostatic Icosahedral Atmospheric Model (NICAM) to carry out sensitivity experiments, Satoh and Kitao (2013) found that the primary mechanism driving the diurnal variations in precipitation over South China is the local forcing rather than the water vapor inflow. Du et al. (2014) analyzed WRF Model results and suggested that the two diurnal modes of low-level jets are generally consistent with the diurnal variations in precipitation.

Most of the previous studies have been confined to the area east of the Leizhou Peninsula (approximately $\left.110^{\circ} \mathrm{E}\right)$. However, the geographical conditions, such as the coastline curvature and onshore terrain, change significantly along the coastline within the $107^{\circ}-115^{\circ} \mathrm{E}$ range in South China (as shown in Fig. 1). Correspondingly, the precipitation features also vary considerably. In this study, the heterogeneity of the hourly precipitation features along the coast of South China will be explored, and the possible reasons for the regional differences in precipitation will be discussed. The results will provide new finescale metrics for the evaluation of NWP products as well as high-resolution climate model outputs.

The remainder of this paper is organized as follows. In section 2, a brief description of the data and analytical methods used in the study are provided. In addition to the climatic precipitation features, the frequency-intensity characteristics of precipitation and the diurnal cycles with different precipitation 

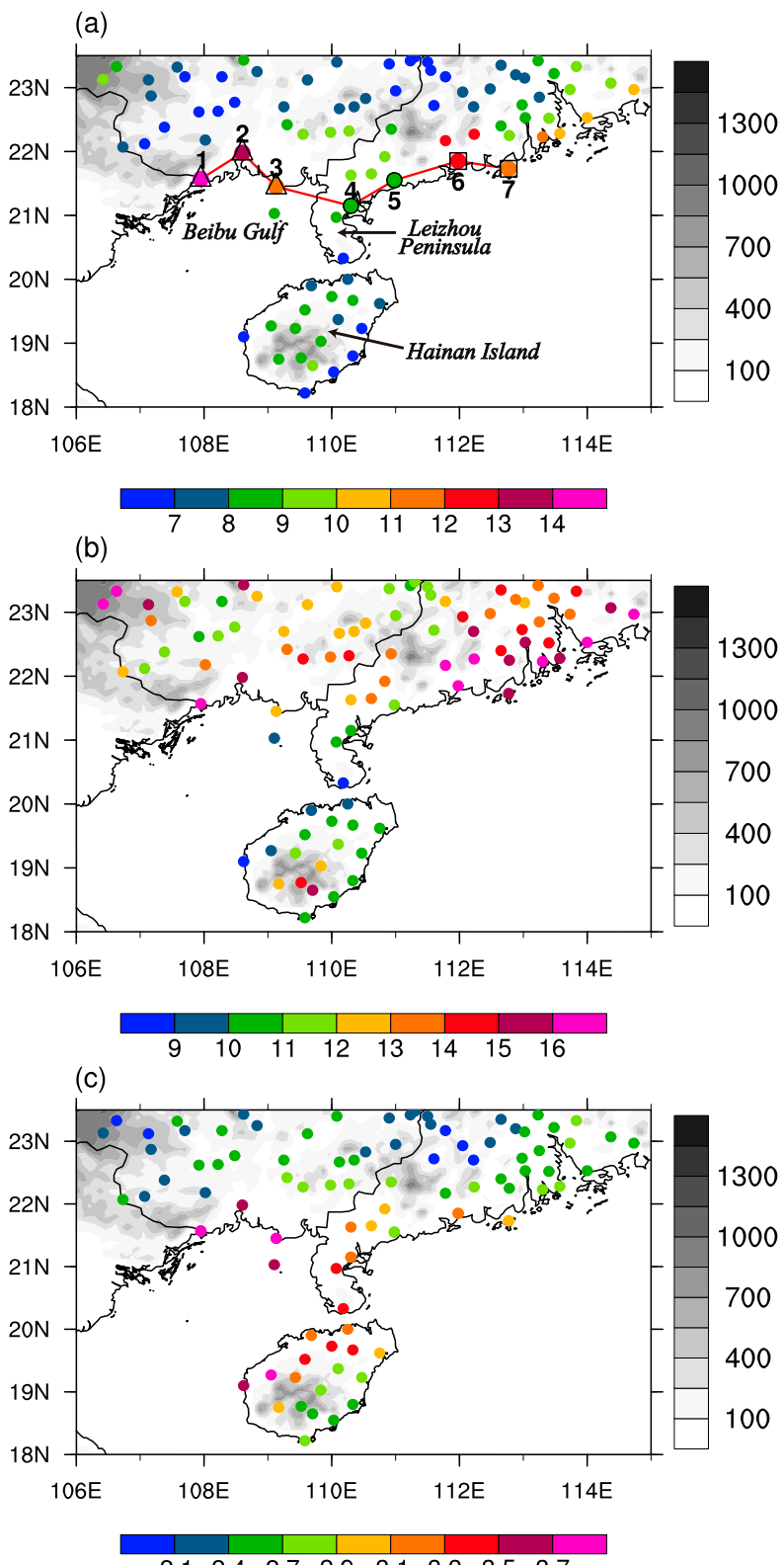

$\begin{array}{llllllll}2.1 & 2.4 & 2.7 & 2.9 & 3.1 & 3.3 & 3.5 & 3.7\end{array}$

FIG. 1. Spatial distributions of summer (June-August) (a) 24-h precipitation amounts $\left(\mathrm{mm} \mathrm{day}^{-1}\right),(\mathrm{b})$ mean frequencies $(\%)$, and (c) intensities $\left(\mathrm{mm} \mathrm{h}^{-1}\right)$ over the coastal areas of South China. The seven stations used in Fig. $2 \mathrm{~b}$ are enlarged and marked with three kinds of symbols and incremental numbers from west to east (the black-outlined triangles and squares represent two large precipitation centers, respectively, and the black-outlined circles represent the dry area). The red solid lines connect the seven stations in Fig. 1a.

durations along the western coast of South China are analyzed and compared in section 3 . In section 4 , the possible reasons for the distinctive hourly precipitation features in different regions along the western coast of South China are presented. The major conclusions of the study and a discussion are provided in section 5 .

\section{Data and method}

Hourly rainfall records from 89 national meteorological stations in South China $\left(18^{\circ}-23.5^{\circ} \mathrm{N}, 106^{\circ}-115^{\circ} \mathrm{E}\right.$, as shown in Fig. 1a) for the 1976-2015 during JuneAugust period were used in this study. The dataset was obtained from the National Meteorological Information Center of the China Meteorological Administration, and the data have undergone strict quality-control procedures (i.e., extreme value check, internal consistency check and time consistency check) (Zhang et al. 2016). The records from the 89 stations during summer (June-August) were analyzed. In addition, a merged rain gauge-satellite gridded hourly precipitation dataset developed by the China Meteorological Administration (CMA) (Shen et al. 2014) was also used in this study (herein, CMPA). This dataset combined the qualitycontrolled hourly precipitation measured by more than 30000 automatic rain gauges from CMA's network with the satellite-retrieved precipitation product from the Climate Prediction Center Morphing Technique (CMORPH; Joyce et al. 2004) using the probability density function-optimal interpolation (PDF-OI) method. The hourly dataset has a resolution of $0.1^{\circ} \times 0.1^{\circ}$ and covers the 2008-15 period.

In this study, the climatological precipitation amount at each station was calculated by dividing the cumulative precipitation amount during the study period (JuneAugust 1976-2015) by the number of nonmissing hours and then multiplying by $24 \mathrm{~h}$ to normalize to 24 -h amount $\left(\mathrm{mm} \mathrm{day}^{-1}\right)$. Precipitation frequency was defined as the percentage of total hours with measurable precipitation $\left(\geq 0.1 \mathrm{~mm} \mathrm{~h}^{-1}\right)$ versus the total nonmissing hours. Precipitation intensity was obtained by dividing the cumulative precipitation amount by the number of hours with measurable precipitation. The start time of a precipitation event was defined as the first measurable precipitation hour after no precipitation for two hours or more. Similarly, the last measurable rainfall hour before two or more dry hours (the hours with no rainfall or rainfall of $<0.1 \mathrm{~mm} \mathrm{~h}^{-1}$ ) was considered to be the end hour of a rainfall event. The duration of a rainfall event was the number of hours from the beginning to the end of one event (Yu et al. 2007). In the composite analysis of precipitation events satisfying the conditions, the composite frequency of precipitation is defined as the number of accumulated hours with measurable precipitation at the corresponding time before or after the start of the events. Local solar time (LST) is used in this study. 
To analyze the atmospheric circulation related to the typical rainfall events in different regions of the western coast of South China, the ERA5 reanalysis data for the 2008-15 period were used in this study. ERA5 is the fifth generation of ECMWF atmospheric reanalysis of the global climate (Hersbach and Dee 2016) and provides hourly analysis fields at a horizontal resolution of $31 \mathrm{~km}$ (http://climate.copernicus.eu/products/ climate-reanalysis; Albergel et al. 2018). The activity of deep convection was analyzed using the hourly temperature of brightness blackbody (TBB) during 2008-15, which was derived from the first infrared (IR1) channel of the Fengyun (FY) geostationary satellites. The data used in this study were from $F Y-2 C$ (2008-09) and its successor $F Y-2 E$ (2010-15). The TBB product was obtained from National Satellite Meteorological Center of the CMA, and it has a resolution of $0.1^{\circ} \times 0.1^{\circ}$. Augustine and Howard (1991) noted that the identification criterion for a mesoscale convective complex is $\mathrm{TBB} \leq-52^{\circ} \mathrm{C}$. According to this criterion, the deep convection at each grid point was identified. The deep convection frequency was defined as the percentage of total numbers of deep convection versus total noninvalid observation times. The tropical cyclone (TC) best-track dataset from the Shanghai Typhoon Institute of the CMA was also used. The rainfall events at each station occurred on the days when one or more TCs located within $500 \mathrm{~km}$ from this station were classified as TC precipitation events.

\section{Distinct hourly precipitation characteristics along the western coast of South China}

Figures $1 \mathrm{a}-\mathrm{c}$ show the spatial distributions of rainfall amounts, frequencies and intensities over the coastal area of South China. Consistent with previous studies (Xu et al. 2009; Xu 2013), summer rainfall is substantial over this region. The precipitation amount exceeds $8 \mathrm{~mm} \mathrm{day}^{-1}$ over the coastal area between $21^{\circ}$ and $22.5^{\circ} \mathrm{N}$, which is generally larger than that over the inland area (Fig. 1a). Along the coastline, the rainfall amount exhibits large regional differences, which are manifested by two heavy precipitation centers, one to the west and the other to the east of the Leizhou Peninsula, and a relatively dry area is located between these two centers. The precipitation frequencies over the two large rainfall regions also present with high values (Fig. 1b). In contrast, the precipitation frequency over the Leizhou Peninsula is low. The precipitation intensity over the coastal area is larger than that over the inland areas, and the general decreasing feature of precipitation intensity from the coastal area to the inland area is similar to that of the precipitation amount. To further quantify the difference along the coast, seven stations near the coastline are selected and are marked by numbers in Fig. 1a. Among the seven stations, the maximum precipitation amount and frequency both appear at station 1 , and the values are $17.0 \mathrm{~mm} \mathrm{day}^{-1}$ and $18.7 \%$, respectively. This station also has the largest precipitation amount among all 89 stations shown in Fig. 1a. Over the area east of the Leizhou Peninsula, the maximum precipitation amount $\left(12.1 \mathrm{~mm} \mathrm{day}^{-1}\right)$ and frequency $(16.2 \%)$ appear at station 6. Over the Leizhou Peninsula, station 4 shows a low precipitation amount $\left(8.1 \mathrm{~mm} \mathrm{day}^{-1}\right)$ and a low precipitation frequency $(10.8 \%)$. Overall, there are tripole patterns in precipitation amount and frequency along the coastline: two precipitation amount centers with high precipitation frequencies are located to the west and east of the Leizhou Peninsula (stations 1-3, marked with triangle and stations 6 and 7, marked with squares) and a relatively dry region with a low precipitation frequency (stations 4 and 5, marked with circles) is located over the Leizhou Peninsula.

To verify whether there are spatial inhomogeneities in the diurnal cycle of precipitation along the coast, the diurnal peak phases of the summer precipitation amount are shown in Fig. 2a. Approximately $83.0 \%$ of the stations reach their maximums between 1200 and 1800 LST. In contrast, morning peaks are found at stations located along the coast of the mainland and the western and southern parts of Hainan Island. Notably, in coastal areas of the Leizhou Peninsula, an afternoon peak is presented, which is similar to the diurnal peaks in the afternoon peaks over the inland region and central Hainan Island. Figure $2 b$ shows the diurnal variations along the profile composed of the seven stations marked in Fig. 1a. There is a tripole pattern in the diurnalcoastline distribution. The first center is over stations 1-3 to the west of the Leizhou Peninsula. The precipitation in this location is mainly concentrated in the morning, and the large-value center lags from west to east. The second center is located to the east of the Leizhou Peninsula (stations 6 and 7) and peaks in the morning. A gap exists between the two morning precipitation centers, and the minimum is located at station 4 . The third and weakest center is located over the Leizhou Peninsula (station 4) in the afternoon. A prominent feature of the diurnal cycles of precipitation along the western coast of South China is the "morning-afternoon-morning" pattern.

The diurnal precipitation feature was further analyzed by the CMPA data with a focus on the detailed distribution of the precipitation percentage in the morning (0400-1000 LST) and afternoon (1200-1800 LST) in comparison with the daily precipitation amount. As shown in Fig. 3a, there are high-value regions of the 
(a)

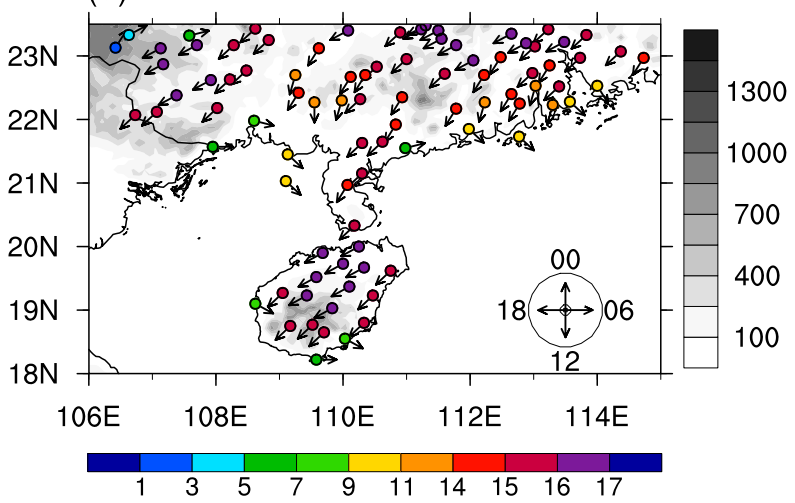

(b)

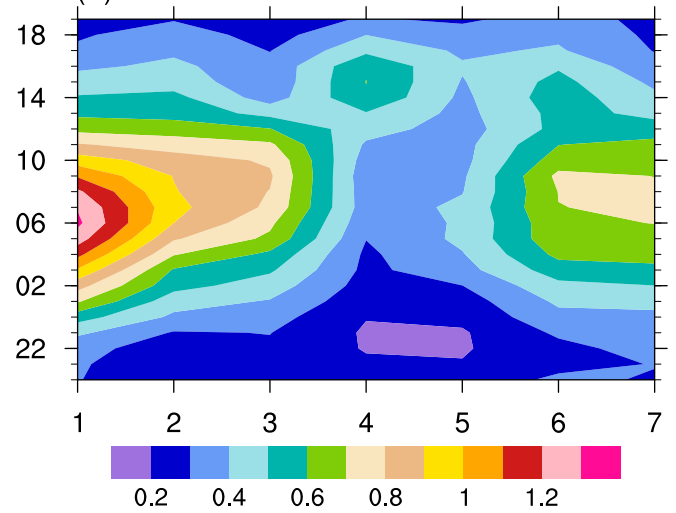

FIG. 2. (a) The diurnal peak phases (LST; arrow direction and colored dots) of the summer precipitation amount over the coastal areas of South China. The direction of the black arrows on the colored dots indicates the time at which the diurnal peak appears. The gray shading represents the terrain height $(\mathrm{m}$; top-right color bar). (b) The time-station distribution of diurnal precipitation amount $\left(\mathrm{mm} \mathrm{h}^{-1}\right)$ for the seven stations along the coastline as marked in Fig. 1a.

morning precipitation percentage distributed along the southern coastline of China except for the Leizhou Peninsula at approximately $110^{\circ} \mathrm{E}$. In addition, the percentage of morning precipitation to the west of the Leizhou Peninsula is higher than that to the east of the Leizhou Peninsula. Another feature is that the percentage of morning precipitation rapidly decreases from the coastal high-value zone (more than $40 \%$ ) to the inland area (less than 20\%). Figure $3 \mathrm{~b}$ shows the percentage distribution of the precipitation in the afternoon. The gradient of afternoon precipitation proportion (from $30 \%$ to $45 \%$ ) over the coastal areas is nearly perpendicular to the coastline. The percentage of afternoon precipitation can reach more than $55 \%$ in the inland area, while the percentage near the coastline is less than $25 \%$. Both the Leizhou Peninsula and Hainan Island present high percentages in Fig. $3 \mathrm{~b}$, and the maximum percentage of afternoon precipitation over Hainan Island is as high as $82.1 \%$. The percentage of precipitation in the morning and afternoon exhibits the opposite spatial pattern, and the spatial correlation coefficient between Figs. $3 \mathrm{a}$ and $3 \mathrm{~b}$ reaches -0.88 .

The above analyses reveal that the precipitation characteristics to the west and east of the Leizhou Peninsula are similar, while the precipitation over the Leizhou Peninsula differs. To reveal more detailed differences in the summer precipitation features along the coastline, three representative stations were chosen for further analysis. An analysis of the hourly precipitation records at the three stations can distinguish precipitation events with different features and mechanisms. The locations of the three stations (Dongxing, Zhanjiang, and Yangjiang) are marked by black solid triangles in Fig. 3a. In Fig. 1a, Dongxing, Zhanjiang, and Yangjiang are station 1 , station 4 , and station 6 , respectively. The Dongxing (Yangjiang) station represents the western (eastern) heavy precipitation centers, and the Zhanjiang station is for the dry region around the Leizhou Peninsula.

The rainfall frequency-intensity distribution is an important feature for characterizing local climate ( $\mathrm{Li}$ and Yu 2014). Figure 4a shows the accumulative summer precipitation frequency at various intensities during 1976-2015 at the three representative stations. Overall, the precipitation frequency decreases with intensity at all stations. Dongxing has the highest precipitation frequency at all intensity ranges. The precipitation frequency with an intensity of $<5 \mathrm{~mm} \mathrm{~h}^{-1}$ at Yangjiang is closer to that at Dongxing, while the difference between the two stations becomes larger with increasing intensity. For Zhanjiang, the frequency with an intensity of $<40 \mathrm{~mm} \mathrm{~h}^{-1}$ is the lowest among the three stations. For frequencies with intensities exceeding $40 \mathrm{~mm} \mathrm{~h}^{-1}$, Zhanjiang is slightly higher than Yangjiang.

Figure $4 \mathrm{~b}$ shows the contributions of different intensity ranges to the total precipitation amount. The Yangjiang (Dongxing) station presents the largest (lowest) proportion of weak precipitation. For precipitation with an intensity equal to or higher than $15 \mathrm{~mm} \mathrm{~h}^{-1}$, the percentage of the total precipitation amount at Dongxing (50.5\%) is higher than that at the other two stations $(45.8 \%$ at Zhanjiang and $44.4 \%$ at Yangjiang). For an intensity of greater than $40 \mathrm{~mm} \mathrm{~h}^{-1}$, the percentage of the total precipitation at Zhanjiang is $12.1 \%$, which is higher than that at Dongxing $(11.1 \%)$ and Yangjiang (11.2\%). The above analyses and the quantitative statistics about the climatological features in precipitation demonstrate that the precipitation at Dongxing has the characteristics of high frequency $(18.7 \%)$ and strong intensity $\left(3.8 \mathrm{~mm} \mathrm{~h}^{-1}\right)$, and the precipitation frequency at Yangjiang is medium (16.2\%) 


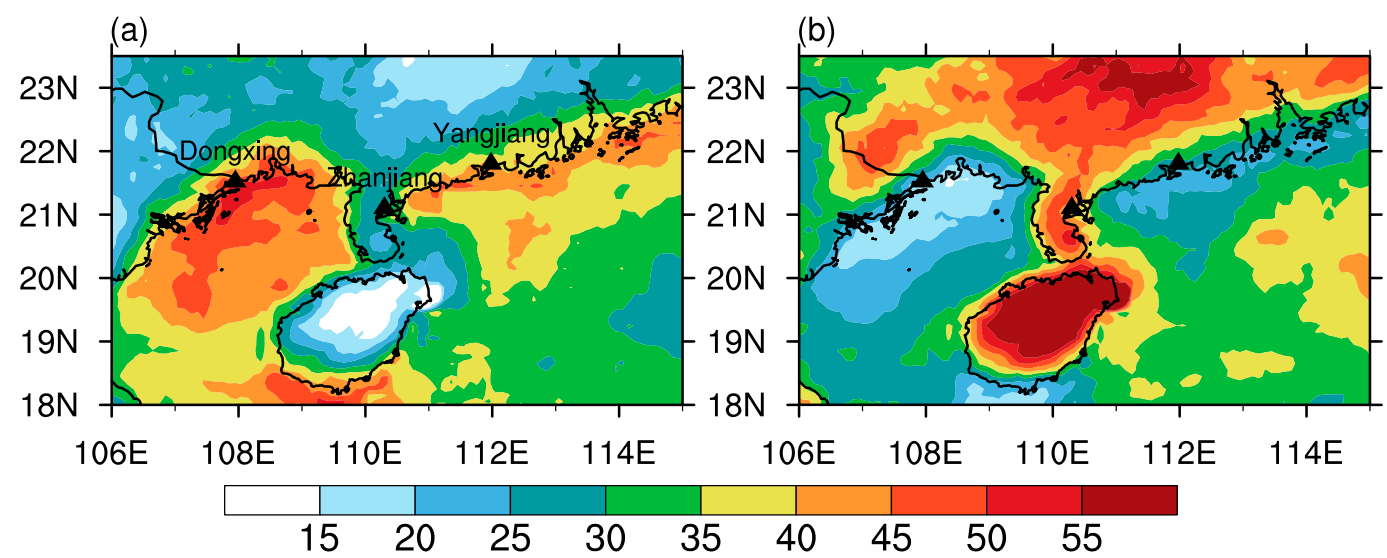

FIG. 3. The percentage of precipitation amount in the (a) morning (0400-1000 LST) and (b) afternoon (1200-1800 LST) in comparison with the daily precipitation amount (\%). The black solid triangles indicate the three representative stations involved in the analysis: from west to east Dongxing, Zhanjiang, and Yangjiang, as labeled in (a).

among the three stations. The actual precipitation frequency at Zhanjiang is as low as $10.8 \%$, and the mean intensity $\left(3.2 \mathrm{~mm} \mathrm{~h}^{-1}\right)$ is slightly higher than that at Yangjiang $\left(3.1 \mathrm{~mm} \mathrm{~h}^{-1}\right)$.

Figure 5a shows the diurnal cycles in precipitation amount at the three stations. The diurnal cycle at Dongxing is characterized by a single-wave pattern and large diurnal amplitude. The peak value occurs at 0600 LST, and the minimum appears at 1800 LST. In contrast, the precipitation at Zhanjiang peaks in the afternoon (1500 LST) and reaches a minimum at night. For the 2100-1300 LST period, the hourly mean precipitation amount at Dongxing is $0.84 \mathrm{~mm} \mathrm{~h}^{-1}$, which is approximately 2.8 times that at Zhanjiang. For the afternoon period from 1400 to 1800 LST, the hourly mean precipitation amount at Zhanjiang $\left(0.54 \mathrm{~mm} \mathrm{~h}^{-1}\right)$ is larger than that at Dongxing $\left(0.38 \mathrm{~mm} \mathrm{~h}^{-1}\right)$. During most of the day, the precipitation amount at Yangjiang lies between the curves of the other two stations. The diurnal cycle at Yangjiang presents a double-peak pattern, with one dominant peak in the morning (0900 LST) and the other peak in the afternoon (1400 LST). The initiation time of precipitation can characterize the triggering of precipitation events. Figure $5 b$ shows the curves of the typical start hours of the precipitation events at the three stations. Generally, the start time curves of precipitation events at the three stations all present double peaks and the peaks mainly appear in the morning and the afternoon. The dominant peak at Dongxing is in the morning (0500 LST) and there are significantly more precipitation events start in the morning than those start in the afternoon. On the contrary, the precipitation events at Zhanjiang tend to start at 1400 LST in the afternoon. For Yangjiang, the morning peak is comparable to the afternoon peak, indicating that the precipitation in this region tends to be triggered both in the morning and afternoon.

As an important feature of the precipitation events, the duration is closely related to the precipitation mechanisms. Yu et al. (2007) revealed that the duration is a key factor in separating different kinds of rainfall events exhibiting different diurnal peaks. The relationship between the duration and diurnal phase of summer precipitation at the three stations was further analyzed by decomposing the accumulated precipitation at the hourly scale by the precipitation event duration to which the hour belongs ( $y$ axis in Fig. 6) and the diurnal phase of the hour ( $x$ axis in Fig. 6). Focusing on the longduration precipitation events, the events at the three stations are mainly contributed by the morning precipitation. However, from the perspective of the overall feature of the duration-diurnal structure, there are distinctive characteristics for each station (Fig. 6). The precipitation at Dongxing mainly occurs in the morning with a long duration (Fig. 6a), and the mean duration of precipitation events at Dongxing is $5.5 \mathrm{~h}$. The maximum cumulative precipitation amount at Dongxing appears at $0600 \mathrm{LST}$, and the events last for $10 \mathrm{~h}$. Approximately $30.4 \%$ of the precipitation amount at Zhanjiang is contributed by short-duration $(<5 \mathrm{~h})$ events, and the precipitation amount is much higher than those at the other two stations $(15.5 \%$ at Dongxing and $19.6 \%$ at Yangjiang). The short-duration precipitation events at Zhanjiang mainly occur in the afternoon. Different from the prior two stations, there are two large-value centers at Yangjiang (Fig. 6c): one with a short duration in the afternoon (centered at 1400 LST) and the other with a long duration in the morning (centered at 0800 LST). The short-duration precipitation center in the afternoon is similar to the Zhanjiang results, but the cumulative 
(a)

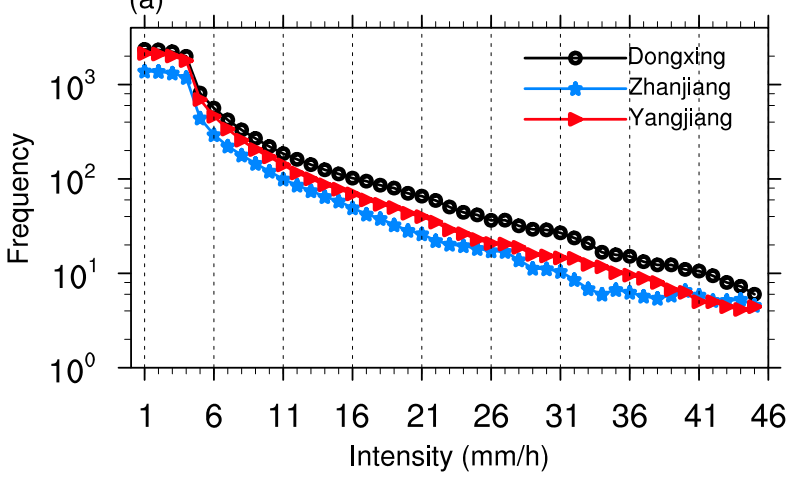

(b)

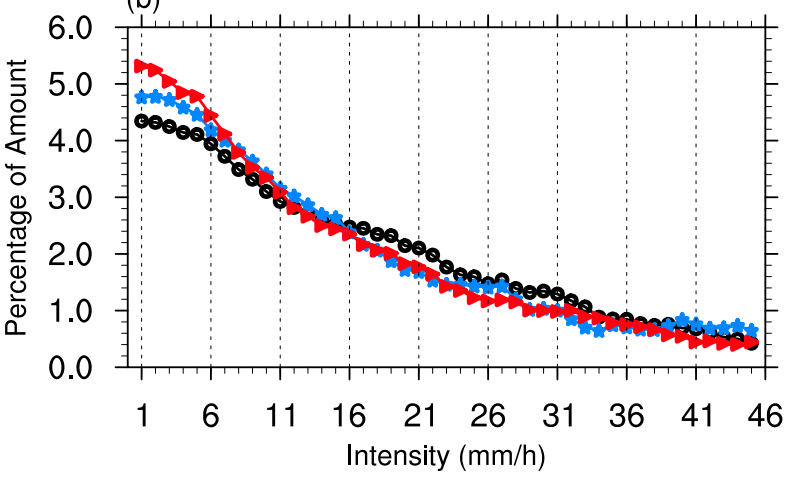

FIG. 4. (a) The precipitation frequency of different intensity ranges and (b) the percentage of precipitation amount of different intensity ranges relative to the total precipitation amount at the three stations. The black line with open circles indicates Dongxing station, the blue line with pentagrams indicates Zhanjiang station, and the red line with triangles indicates Yangjiang station.

amount of this precipitation event type is less than that at Zhanjiang. The long-duration precipitation center in the morning is similar to the Dongxing results but also with a lower accumulative amount. In general, the precipitation properties among the three stations exhibit significant differences. Dongxing is dominated by long-duration precipitation events in the morning, and Zhanjiang is mainly influenced by short-duration afternoon precipitation. Yangjiang is characterized by the coexistence of both kinds of precipitation events.

\section{Possible reasons for the distinctive rainfall events in different regions of the western coast of South China}

As mentioned in section 3, heavy precipitation frequently occurs at Dongxing, and the precipitation intensity is the strongest among the three stations. Heavy precipitation is often related to MCSs (Houze et al. 1990). Figure 7a shows the distribution of the deep convection frequency averaged for the 2008-15 summers, and (a)

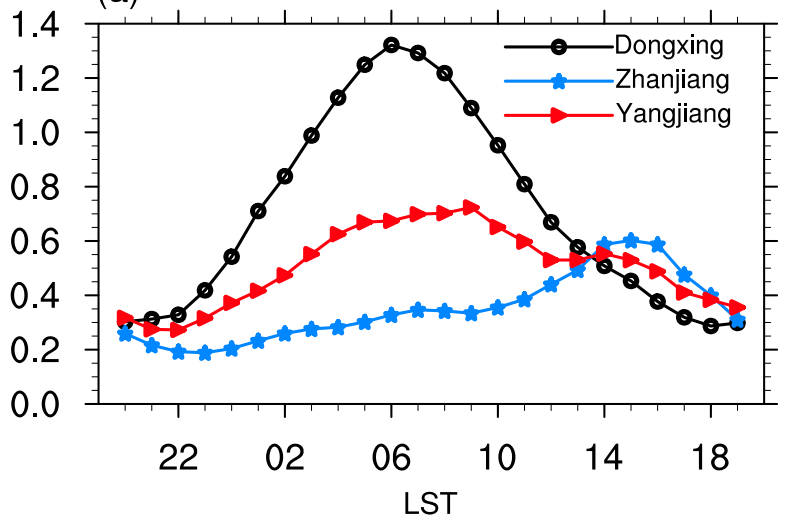

(b)

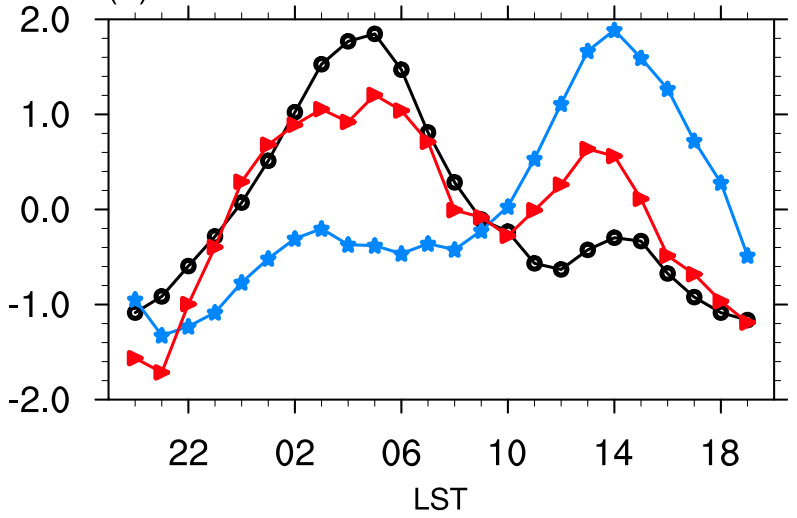

FIG. 5. The diurnal cycles of (a) average precipitation amounts for 40 summers (June-August 1976-2015) $\left(\mathrm{mm} \mathrm{h}^{-1}\right)$ and (b) normalized occurrence frequencies of precipitation events with start hours at each LST at the three stations marked in Fig. 3. The black line with open circles indicates Dongxing station, the blue line with pentagrams indicates Zhanjiang station, and the red line with triangles indicates Yangjiang station. The $x$ axis denotes LST.

the spatial pattern is consistent with the results of Zheng and Chen (2013). There are high frequencies of deep convection over the northern Beibu Gulf and surrounding coast. Dongxing has a frequency of $9.1 \%$ and is very close to the maximum deep convection frequency offshore $(9.5 \%)$. The frequency gradually decreases eastward along the coastline. After reaching the local minimum value $(6.4 \%)$ at approximately $111^{\circ} \mathrm{E}$, the deep convection frequency increases eastward and reaches $7.2 \%$ near Yangjiang. In addition, there is another high-frequency center over northwestern part of Hainan Island. As shown in Fig. 7b, the diurnal variation in the deep convection frequency at Dongxing presents a double-peak pattern. The primary peak occurs in the morning ( $13.7 \%$ at 0700 LST), which corresponds well with the diurnal peak in precipitation frequency at Dongxing (not shown). The secondary peak occurs in the late afternoon (9.3\% at 1700 LST). Both Zhanjiang and Yangjiang present a single afternoon 
(a)

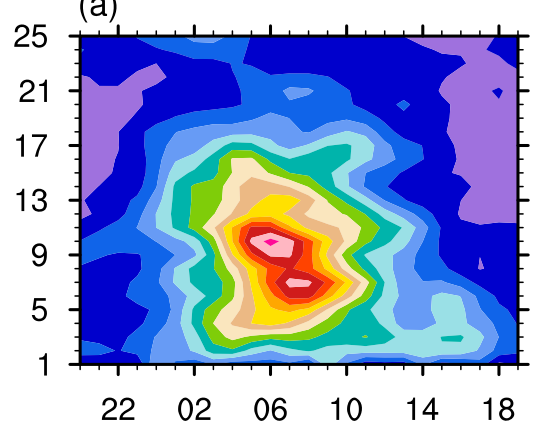

(b)

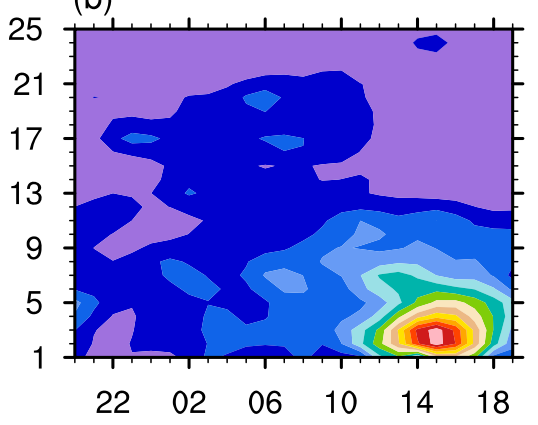

(c)

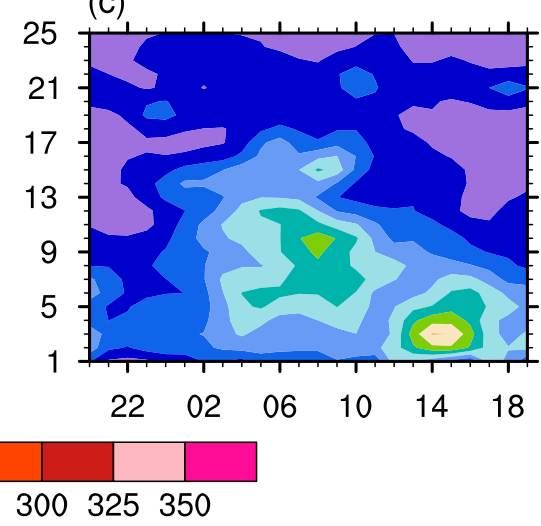

FIG. 6. The accumulated precipitation amounts for 40 summers (June-August 1976-2015) with different durations ( $y$ axis) and in different diurnal phases ( $x$ axis) (mm) at (a) Dongxing station, (b) Zhanjiang station, and (c) Yangjiang station.

peak, and the maximum frequency at the two stations is comparable. The maximum frequency at Zhanjiang $(10.5 \%)$ appears at $1500 \mathrm{LST}$, which is one hour later than that at Yangjiang (10.4\%). According to the diurnal curves in Fig. 7b, the deep convection frequencies in the morning (0400-1000 LST) and afternoon (12001800 LST) were calculated and are presented separately. In the morning (Fig. 7c), the high-frequency
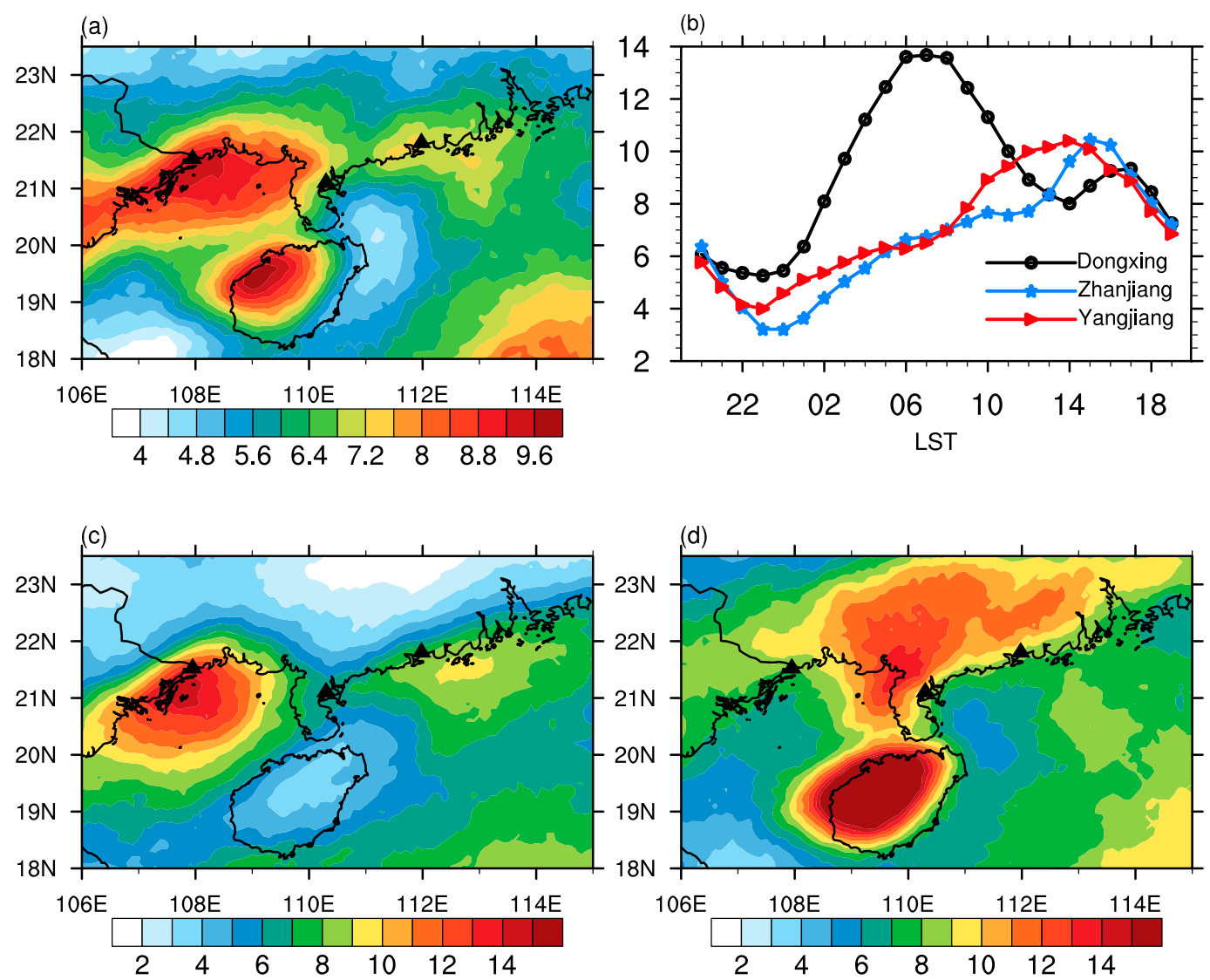

FIG. 7. (a) Distributions of summer mean frequency of the deep convection (\%) derived from the FY-2 geostationary satellites during 2008-15, and (b) the diurnal cycle of the deep convective frequency at the grids that are nearest to the three stations. Also shown is the accumulative frequency of deep convection (c) in the morning (0400-1000 LST) and (d) afternoon (1200-1800 LST) during 2008-15 (\%). The black solid triangles from west to east indicate Dongxing, Zhanjiang, and Yangjiang. 
center over the Beibu Gulf is similar to that in Fig. 7a. The offshore convective center to the east of Yangiiang (approximately $113^{\circ} \mathrm{E}$ ) in Fig. $7 \mathrm{c}$ coincides with that in Fig. 7a, but the local maximum around Yangjiang and onshore is missing in Fig. 7c. Zhanjiang is located just between the two centers and presents the local lowest frequency $(6.7 \%)$. In contrast, the afternoon deep convection (Fig. 7d) mainly appears over the inland area and Hainan Island, and the frequency at Dongxing is lower than that at the other two stations. An analysis of the spatial distribution and diurnal variation in the deep convection frequency reveals that the morning precipitation at Dongxing is closely related to the deep convection. Another point is that the afternoon precipitation at Yangjiang and Zhanjiang may be influenced by the deep convection.

The regional differences in the deep convection characteristics indicate that the processes responsible for the precipitation in the three regions are different, and the possible reasons were further examined based on the evolution of precipitation events and their corresponding circulations. The precipitation events during 2008-15 were identified at each station based on the hourly rain gauge data, and in addition to the evolution of the precipitation events, the preevent conditions were also considered. The CMPA data were also used to describe the continuous spatial distribution of precipitation during each event. The precipitation events related to TCs were excluded.

\section{a. Dongxing}

There are 257 morning precipitation events that occurred at Dongxing, and the maximum precipitation occurred during 0400-1000 LST. Among these events, 71 were selected with durations of $>6 \mathrm{~h}$ and a maximum hourly precipitation amount of $\geq 3 \mathrm{~mm} \mathrm{~h}^{-1}$. The circulation associated with the 71 heavy precipitation events can be classified into three regimes, and the precipitation during each regime presents distinctive characteristics. The first regime is affected by the weather systems moving from the inland, and this regime contains 15 precipitation events. The mean duration of these events is $13.2 \mathrm{~h}$, and the mean maximum hourly precipitation amount is $19.1 \mathrm{~mm} \mathrm{~h}^{-1}$. Figures $8 \mathrm{a}-\mathrm{d}$ show a case with the influence of the inland synoptic system. These four plots show the distribution of hourly precipitation amount and circulation $6 \mathrm{~h}$ before the start time of the event at Dongxing (Fig. 8a), $3 \mathrm{~h}$ before the start time (Fig. 8b), the start time (Fig. 8c) and $3 \mathrm{~h}$ after the start time (Fig. $8 \mathrm{~d}$ ) of the precipitation event. At Dongxing, this precipitation event lasted for $15 \mathrm{~h}$ and peaked at 0600 LST on 10 June 2013. There was a shear line at $850 \mathrm{hPa}$ (thick brown lines in Figs. 8a-d) between the southwesterly wind and northeasterly wind. The rain belt that accompanied the shear line gradually moved southward.

In the second regime, there are 12 precipitation events. A common feature of these precipitation events is the influence of marine weather systems, such as the low pressure center over the Beibu Gulf. In comparison with the first regime of precipitation events, this category of precipitation events has a longer mean duration $(14.6 \mathrm{~h})$ and a stronger mean maximum hourly precipitation amount $\left(23.4 \mathrm{~mm} \mathrm{~h}^{-1}\right)$ at Dongxing. Figures $8 \mathrm{e}-\mathrm{h}$ present a case with the influence of a vortex over the Beibu Gulf. The precipitation at Dongxing occurred on 15 June 2013 and peaked at 0100 LST on the following day. As shown in the 3-h evolution (Figs. 8e-h), the vortex over the Beibu Gulf gradually moved northwestward. The rainfall area that accompanied the vortex gradually moved westward and initiated the precipitation event at Dongxing (Fig. 8g).

Figure 9 shows the composite circulations for the first two regimes that influence the long-lasting early morning precipitation at Dongxing. For the 15 cases influenced by the inland synoptic system, the anomalous negative $850-\mathrm{hPa}$ geopotential dominates the inland area at $6 \mathrm{~h}$ before the start time of precipitation events (Fig. 9a). Correspondingly, the total column water vapor over the inland area presents a large positive anomaly. The system moves southward accompanied by sufficient water vapor, which affects Dongxing and makes precipitation occur here (Fig. 9b). In contrast, the anomalous negative $850-\mathrm{hPa}$ geopotential dominates the Beibu Gulf for the 12 cases influenced by the marine synoptic system, and the abundant water vapor comes from the Beibu Gulf (Fig. 9c). The strengthened low pressure system extends northward with sufficient water vapor, and the large-value center of anomalous water vapor has advanced to the region at the start of the Dongxing precipitation events (Fig. 9d).

The third regime is the locally triggered precipitation influenced by the southerly wind and inland topographic barrier. There are 44 events in this regime, accounting for nearly two-thirds of all the morning long-duration precipitation events. The mean duration of this category of events is relatively short $(10.4 \mathrm{~h})$, and the mean maximum hourly amount is $19.7 \mathrm{~mm} \mathrm{~h}^{-1}$. From the composite analysis of this regime of precipitation events, Figs. 10a-d show the distribution of cumulative frequency at $2 \mathrm{~h}$ before the start time (Fig. 10a), $1 \mathrm{~h}$ before the start time (Fig. 10b), the start time (Fig. 10c) and $1 \mathrm{~h}$ after the start time (Fig. 10d) of the 44 precipitation events at Dongxing. The vectors indicate the mean $975-\mathrm{hPa}$ wind field of the 44 events. There are southerly winds over the coastal region, and 

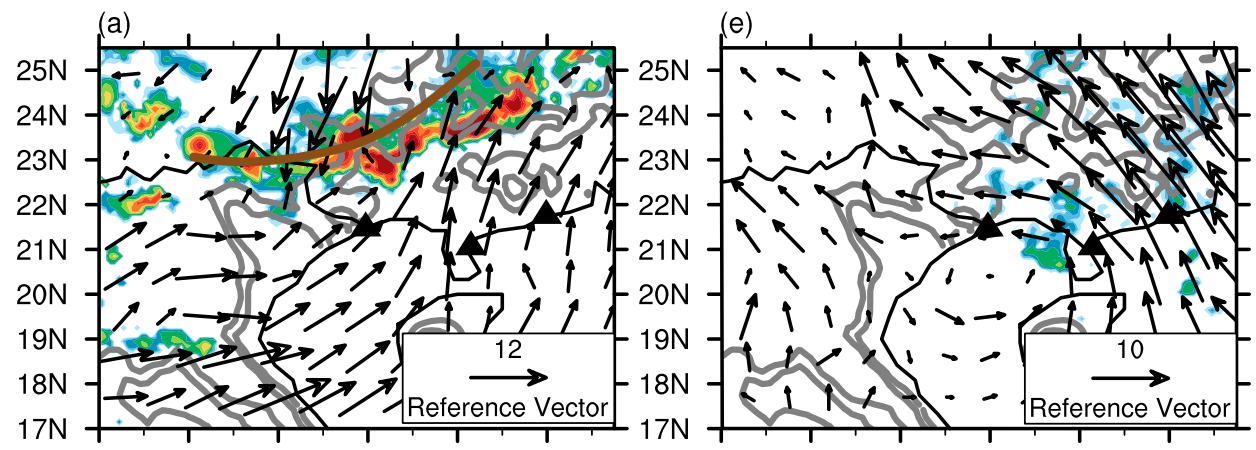

\begin{abstract}
102E 104E 106E 108E 110E 112E
\end{abstract}

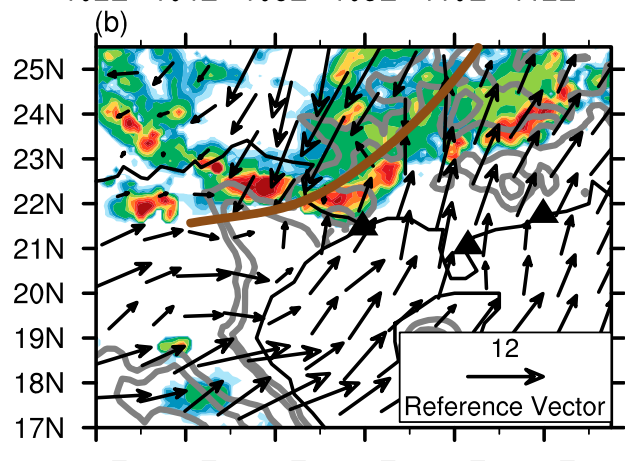

102E 104E 106E 108E 110E 112E
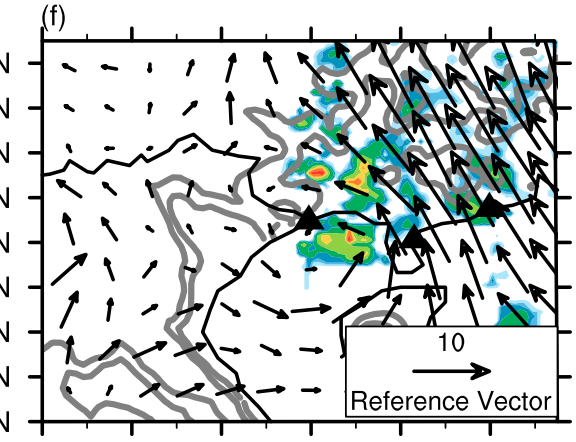

102E 104E 106E 108E 110E 112E

102E 104E 106E 108E 110E 112E
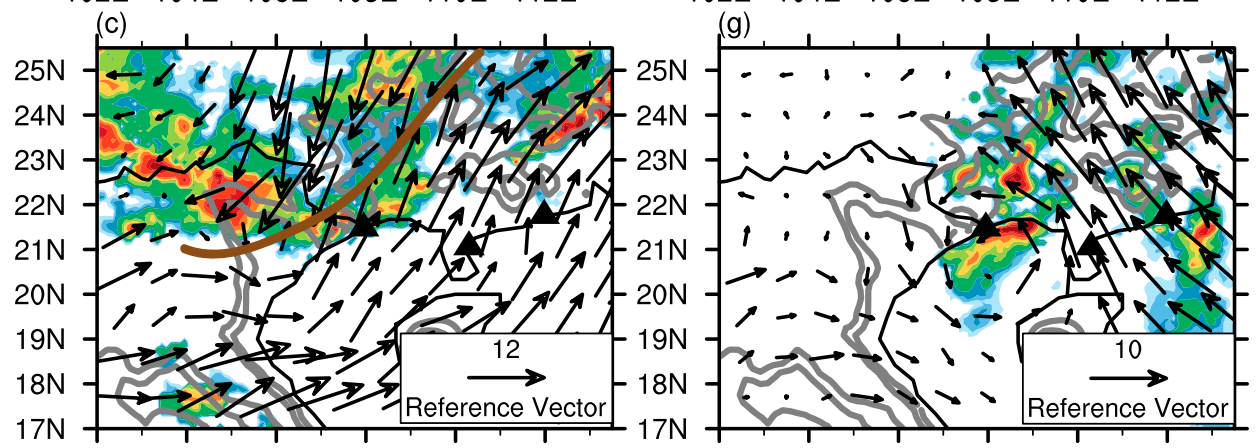

102E 104E 106E 108E 110E 112E

102E 104E 106E 108E 110E 112E
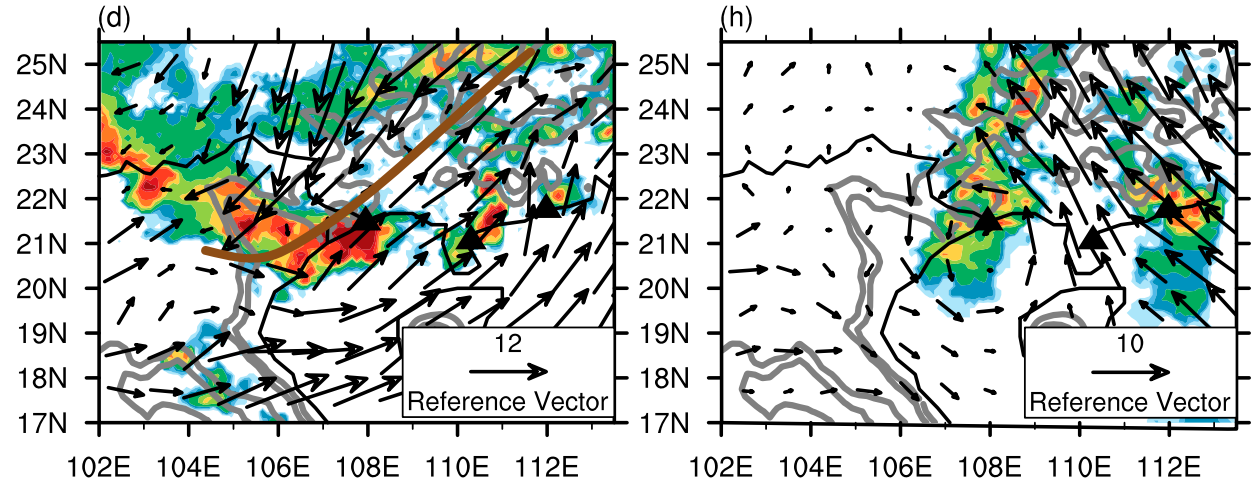

FIG. 8. (left),(right) Two typical cases, showing the precipitation process accompanied by the synoptic system in the inland area (Beibu Gulf). with long-lasting precipitation in the morning at Dongxing that are influenced by different synoptic systems, showing conditions (a),(e) $6 \mathrm{~h}$ before the start time, (b),(f) $3 \mathrm{~h}$ before the start time, (c), (g) at the start time of events, and (d),(h) $3 \mathrm{~h}$ after the start of events at Dongxing. The shading represents the hourly precipitation amount $\left(\mathrm{mm} \mathrm{h}^{-1}\right)$, and the vector denotes the wind at $850 \mathrm{hPa}\left(\mathrm{m} \mathrm{s}^{-1}\right)$. The thick brown lines in (a)-(d) indicate the shear lines. The gray contours represent the topographic heights at 200 and $400 \mathrm{~m}$. The black triangles from west to east indicate Dongxing, Zhanjiang, and Yangjiang. 

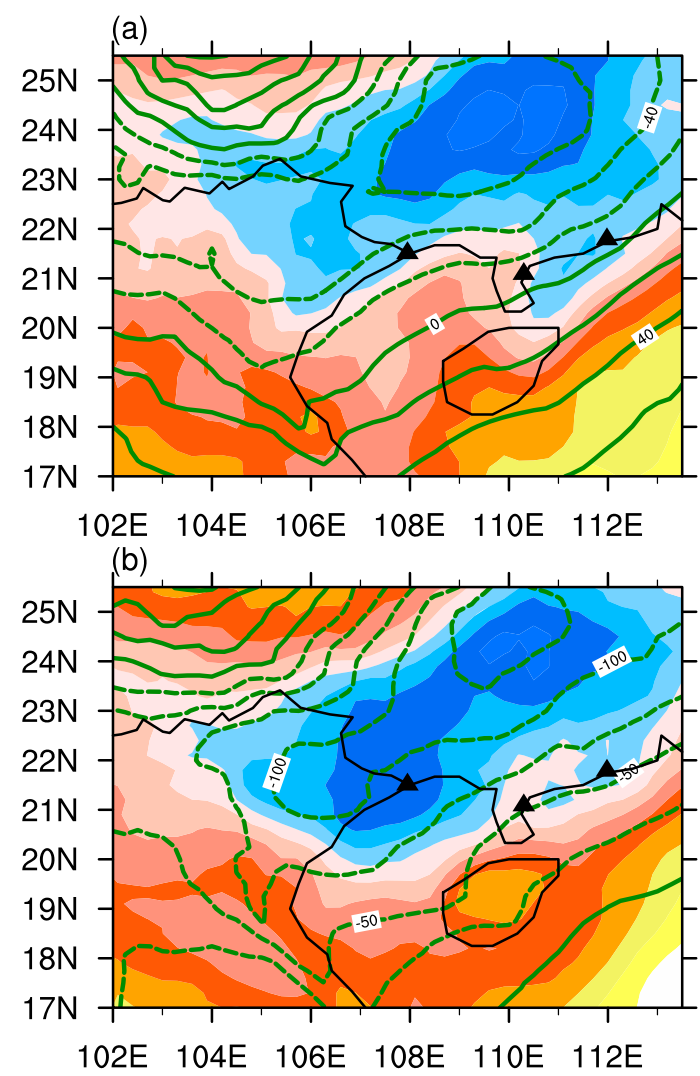

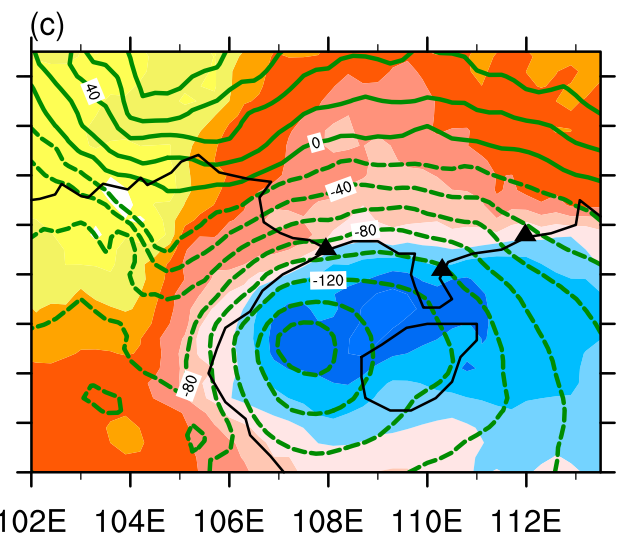

(d)

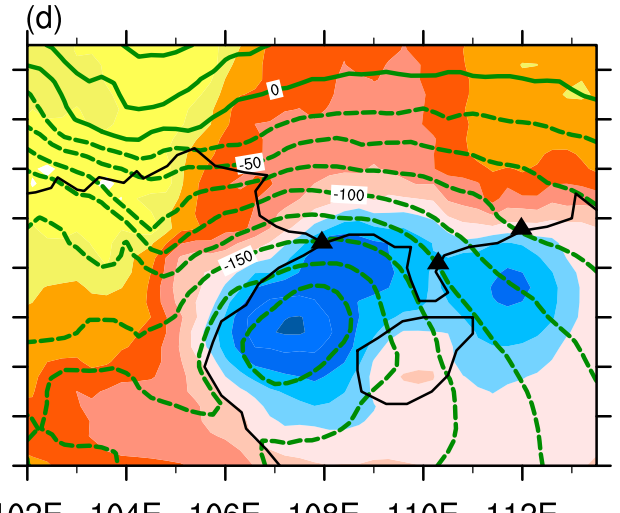

102E 104E 106E 108E 110E 112E

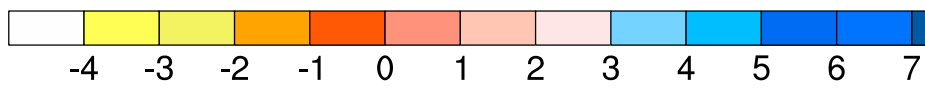

FIG. 9. The composite circulations for the 15 inland and 12 marine synoptic systems that influence the long-lasting precipitation in the morning at Dongxing for (a),(c) $6 \mathrm{~h}$ before the start time and (b),(d) at the start time of events at Dongxing. The shading is the anomalous total column water vapor relative to the climatic total column water vapor $\left(\mathrm{kg} \mathrm{m}^{-2}\right)$. The green contours represent the anomalous 850 -hPa geopotential field (relative to the climatic 850 -hPa geopotential; $\mathrm{m}^{2} \mathrm{~s}^{-2}$ ), dashed lines represent the negative anomalies, and solid lines represent positive anomalies.

the wind speed is approximately $7 \mathrm{~m} \mathrm{~s}^{-1}$. When the strong airflow encounters the topography to the northwest of Dongxing, the precipitation tends to be locally triggered. As shown in Figs. 10a-d, this kind of precipitation appears around the foot of the mountain and influences Dongxing 1-2 h later.

\section{b. Yangjiang}

At Yangjiang, there are 41 morning precipitation events (the maximum hourly precipitation amount appears during 0400-1000 LST) with durations of $>6 \mathrm{~h}$ and a maximum hourly precipitation amount of $\geq 3 \mathrm{~mm} \mathrm{~h}^{-1}$. Figure 11 shows the divergence of the anomalous $10-\mathrm{m}$ wind (relative to the climatic mean $10-\mathrm{m}$ wind) $1 \mathrm{~h}$ before the 41 events were recorded at Yangjiang. There is an anomalous convergence zone along the coastline of South China, which is mainly located in the coastal ocean, and the maximum value reaches $-2.2 \times 10^{-5} \mathrm{~s}^{-1}\left(21.5^{\circ} \mathrm{N}, 111.7^{\circ} \mathrm{E}\right.$, south of
Yangjiang). Simultaneously, an anomalous divergence occurs over the inland mountainous area of South China, just to the northwest of Yangjiang. As noted by Chen et al. $(2015,2016)$, the morning precipitation over this region is closely related to the convergence that is contributed by the land breeze and southwesterly or southerly flow. The mountain-plain solenoid produced by the coastal terrain can combine with the land breeze to enhance offshore convergence (Chen et al. 2016). It is worth noting that the mechanisms affecting the morning precipitation here is very complicated (Zheng et al. 2019). Apart from the influences mentioned above, many other possible factors have been demonstrated by previous studies, such as a gravity wave (Du and Rotunno 2018), eastward-propagating MCSs (Chen et al. 2013), and cold pool dynamics (Chen et al. 2016; Zhu et al. 2017). The cloud-top radiative cooling effect and the enhanced radiative cooling over inland cloud-free areas also play roles in the development 
(a)

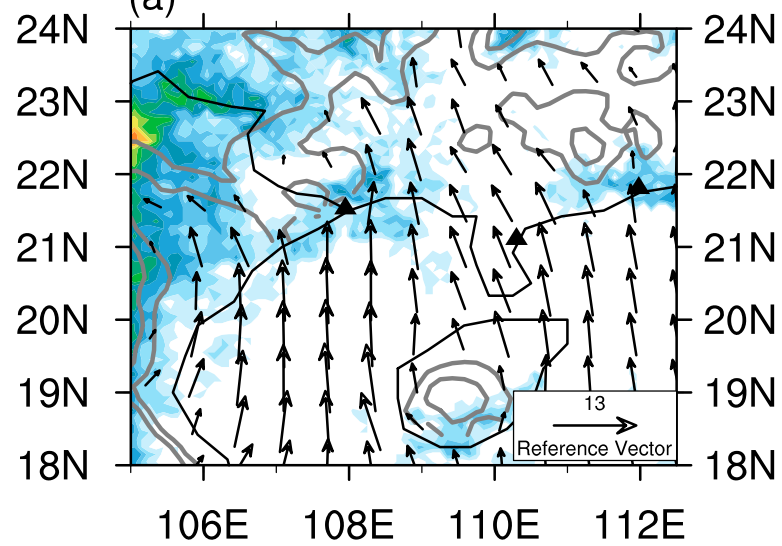

(c)

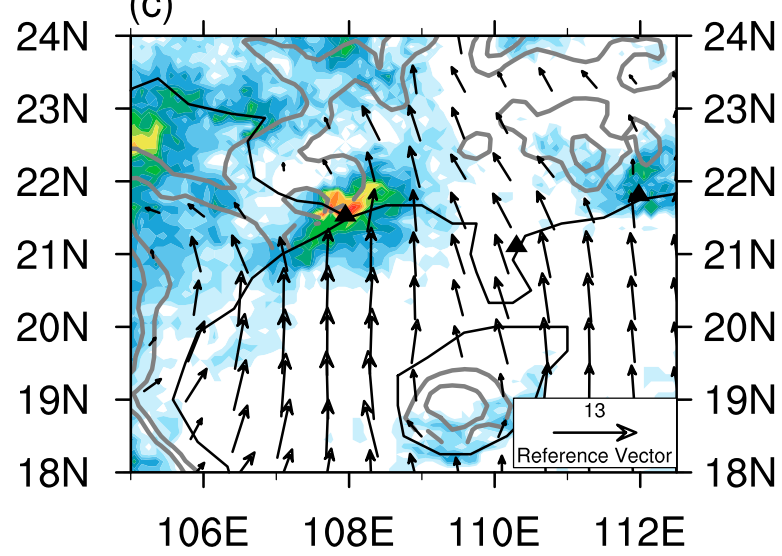

(b)

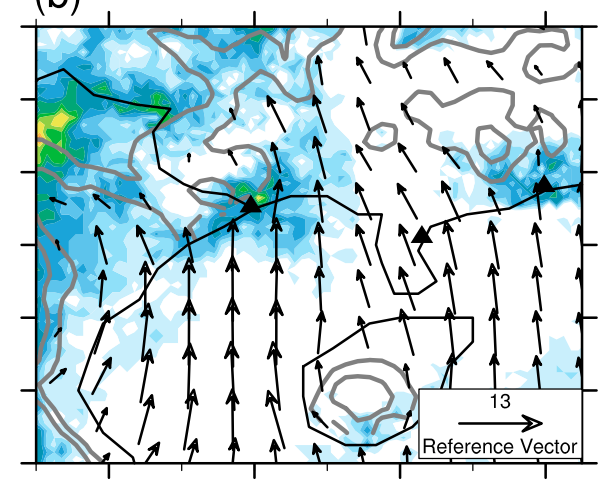

(d)

106E 108E 110E 112E
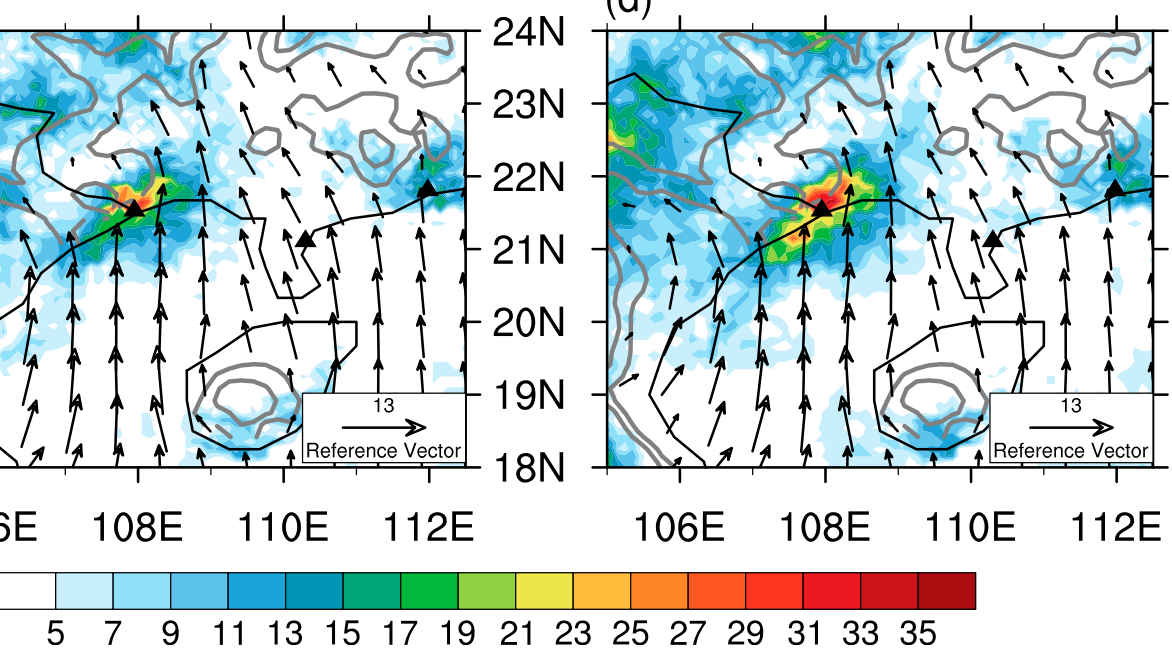

FIG. 10. The distribution of composite precipitation frequency and corresponding 975-hPa wind field at (a) $2 \mathrm{~h}$ before the start time, (b) $1 \mathrm{~h}$ before the start time, (c) the start time, and (d) $1 \mathrm{~h}$ after the start time for the 44 locally triggered long-duration precipitation events in the morning at Dongxing. The shading is the composite precipitation frequency, and the vector denotes the wind at $975 \mathrm{hPa}$. The gray contours represent topographic heights at 200 and $400 \mathrm{~m}$.

of the morning rainfall peak near the coastline of South China (Li et al. 2018).

In addition to the long-duration morning precipitation, Yangjiang also has a considerable amount of shortduration afternoon precipitation (Fig. 6c). There are 31 afternoon short-duration precipitation events, which were defined with durations of $<5 \mathrm{~h}$ and a maximum hourly precipitation amount of $\geq 3 \mathrm{~mm} \mathrm{~h}^{-1}$, which appeared during 1300-1700 LST. A composite analysis of these events at Yangjiang was performed, and Figs. $12 \mathrm{a}-\mathrm{d}$ present the composite frequency of precipitation $2 \mathrm{~h}$ before the start time, $1 \mathrm{~h}$ before the start time, the start time, and $1 \mathrm{~h}$ after the start time of the precipitation events at Yangjiang. The afternoon precipitation events at Yangjiang are mainly triggered by the mountain to the northwest of the station. The southerly flow from the ocean converges after encountering the mountain, which is prone to trigger precipitation. The precipitation usually first occurs over the southeastern slopes of the mountain (Fig. 12a) and then moves southeastward to Yangjiang.

\section{c. Zhanjiang}

As for Zhanjiang, there were 113 short-duration (durations of $<5 \mathrm{~h}$ ) precipitation events with the maximum hourly precipitation amount appearing during 1300-1700 LST. Among these events, the number of events with a maximum hourly precipitation amount of $\geq 3 \mathrm{~mm} \mathrm{~h}^{-1}$ is 55 , which is greater than that at Yangjiang (31 events). Figure 13 shows the divergence of anomalous $10 \mathrm{~m}$ wind $1 \mathrm{~h}$ before these precipitation events. The coastal oceanic areas were controlled by divergence, while a strong convergence can be found over Hainan Island, the Leizhou Peninsula, and the inland mountainous 


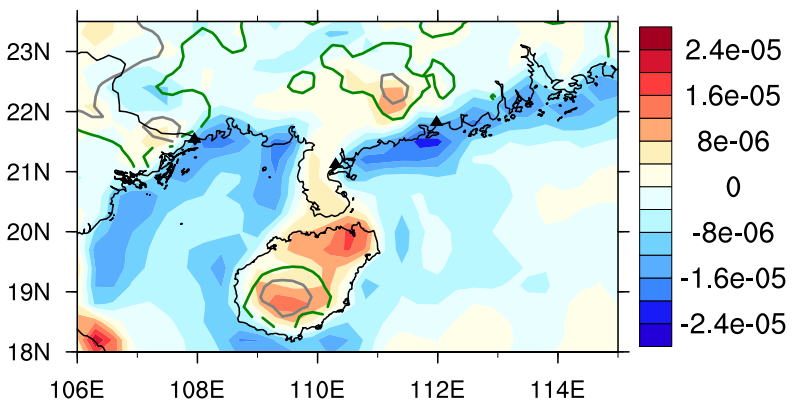

FIG. 11. The divergence distribution of the anomalous $10-\mathrm{m}$ wind (relative to the climatic $10-\mathrm{m}$ wind) $1 \mathrm{~h}$ before the start time of the long-duration morning precipitation events at Yangjiang $\left(\mathrm{s}^{-1}\right.$; note that the "e" indicates "times 10 raised to the sign and digits that follow it"). The topographic heights at 200 and $400 \mathrm{~m}$ are indicated by green and gray contours, respectively. The black triangles from west to east indicate Dongxing, Zhanjiang, and Yangjiang.

areas. The convergence near Zhanjiang exceeds $-2.4 \times$ $10^{-5} \mathrm{~s}^{-1}$, which serves as a key triggering factor of the short-duration afternoon precipitation events in that location. The precipitation events at Zhanjiang frequently start at 1400 LST (Fig. 5b), and the divergence field of climatic $10 \mathrm{~m}$ wind perturbation at 1400 LST (subtracting the daily mean $10 \mathrm{~m}$ wind; not shown) presents similar feature to that in Fig. 13. The anomalous sea breeze converges over the Leizhou Peninsula, which indicates that the convergence responsible for the afternoon precipitation at Zhanjiang results from the diurnal wind perturbations. This mechanism is similar to that noted by Zhu et al. (2017). They found the diurnal cycle of precipitation over Hainan Island is related to low-level convergence associated with the sea-breeze circulations.

At Zhanjiang, there is no morning precipitation peak, which is the reason why the precipitation is lower in this location than that at the other two stations. Influenced by the shoreline curvature, the direction of the land breeze varies along the coastline (Neumann 1951; Baker et al. 2001). The morning land breeze and southwesterly or southerly flow result in divergence at Zhanjiang (Fig. 11), in contrast to the morning coastal convergence near Yangjiang. In addition, due to the relatively flat terrain of the Leizhou Peninsula, there is no locally triggered morning precipitation influenced by
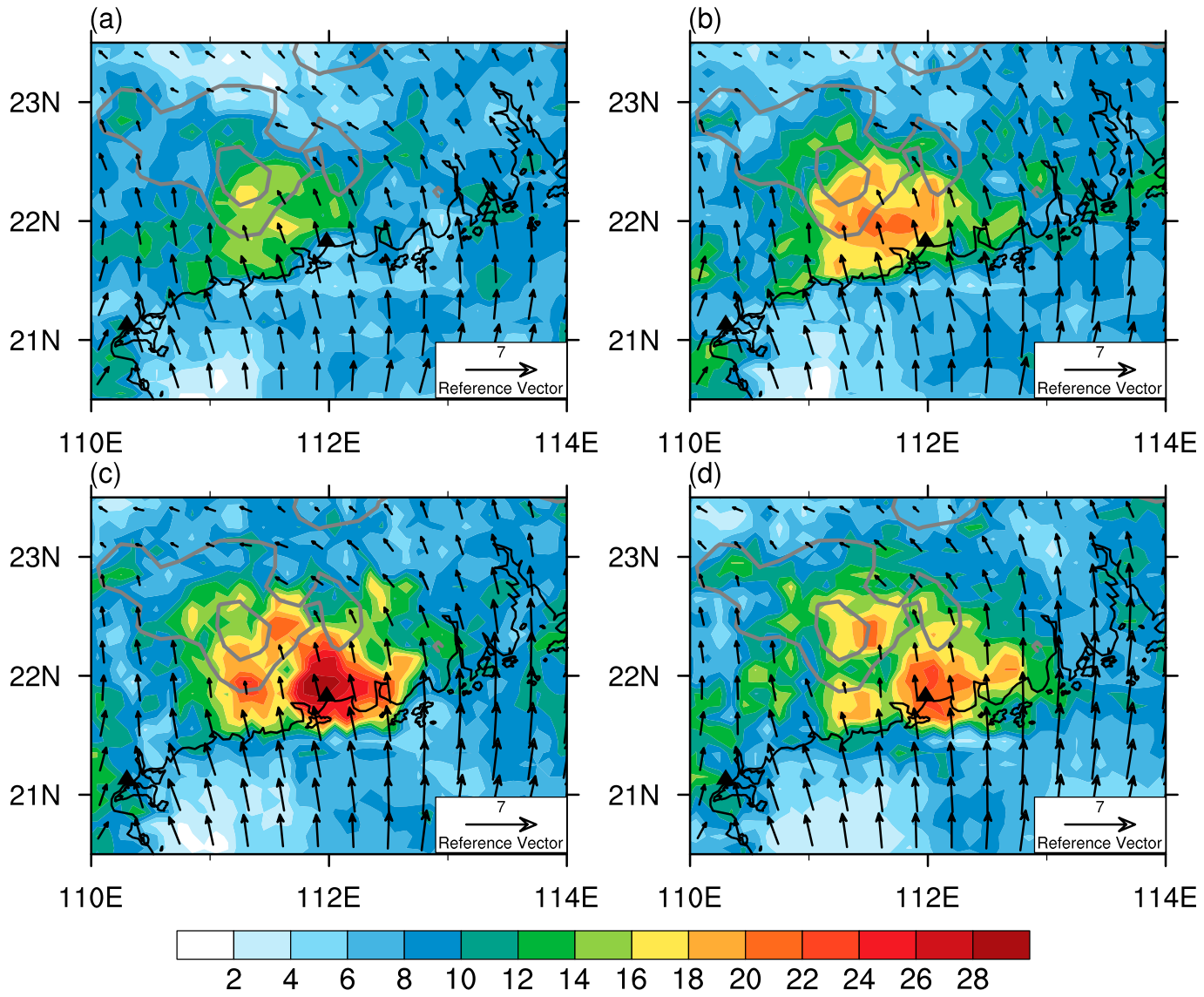

FIG. 12. As in Fig. 10, but for 31 afternoon short-duration precipitation events at Yangjiang. The black triangles from west to east indicate Zhanjiang and Yangjiang. 


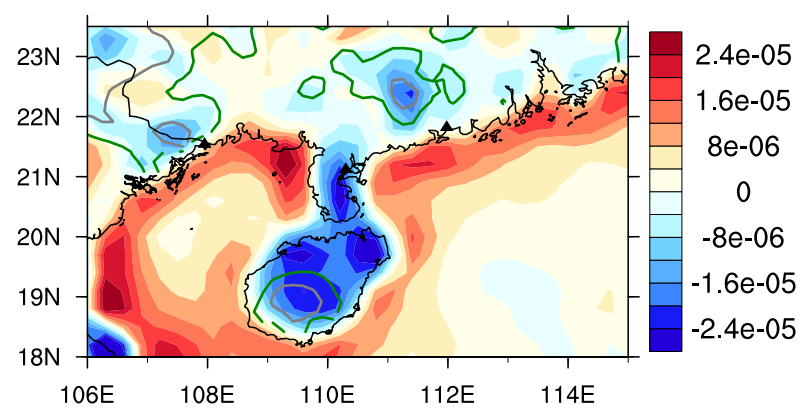

FIG. 13. As in Fig. 11, but for the short-duration afternoon precipitation events at Zhanjiang.

the southerly wind and inland topographic barrier like Dongxing. The absence of two different morning precipitation types leads to relatively less precipitation at Zhanjiang than the other two stations.

\section{Summary and discussion}

In this study, the regional differences in hourly precipitation characteristics along the western coast of South China are investigated using national rain gauge observations and merged precipitation product. The possible reasons for the distinctive precipitation features along the coastline are discussed. The major conclusions are summarized below.

1) Along the western coast of South China, the distributions of precipitation amount and frequency present tripole patterns. Correspondingly, the diurnal peaks in precipitation amount along the coast present a "morning-afternoon-morning" pattern. That is, there are two precipitation amount centers with high precipitation frequencies located to the west and east of the Leizhou Peninsula, and the diurnal peaks in precipitation in that location occur in the morning. The Leizhou Peninsula is a relatively dry region with a low precipitation frequency, and the diurnal precipitation amount presents an afternoon peak.

2) The diurnal variation in precipitation at Dongxing (a representative station to the west of the Leizhou Peninsula) exhibits a single early morning peak at 0600 LST, and the morning precipitation events have long durations. Yangjiang (a representative station to the east of the Leizhou Peninsula) shows two kinds of precipitation: one kind is short-duration precipitation in the afternoon, and the other kind is longlasting precipitation in the morning. The coexistence of two kinds of precipitation corresponds to the double-peak pattern in precipitation diurnal cycle, with one dominant peak in the morning (0900 LST) and the other peak in the afternoon (1400 LST).

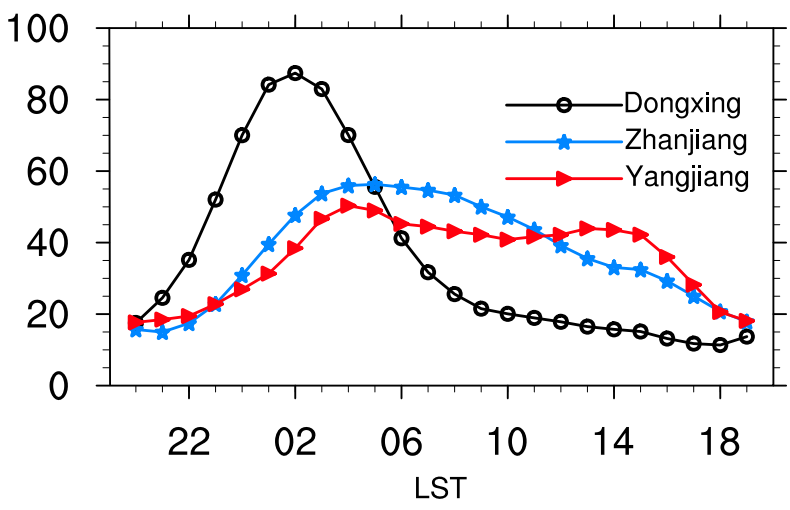

FIG. 14. The diurnal cycle of the occurrence number of $925-\mathrm{hPa}$ strong wind (wind speeds $>12 \mathrm{~m} \mathrm{~s}^{-1}$ ) during 2008-15 at the grids that are nearest to the three stations.

Although the diurnal variation in precipitation at Zhanjiang on the Leizhou Peninsula also exhibits a single-peak pattern, the precipitation over this region is mainly concentrated in the afternoon with a maximum appearing at 1500 LST, and the afternoon precipitation events present short durations.

3) The long-duration morning precipitation events at Dongxing are closely related to the deep convection near the Beibu Gulf. Frequent deep convective activities are responsible for the strongest precipitation intensity at Dongxing among the three stations. In addition, the dominant long-duration morning precipitation events at Dongxing can be classified into three regimes. Apart from the precipitation associated with the synoptic systems over the inland or the Beibu Gulf influencing Dongxing, there is also one precipitation regime generated locally under the influence of a strong southerly wind and inland terrain. The mechanisms affecting the morning precipitation at Yangiiang are complicated, and one possible mechanism is the convergence between the land breeze and prevailing onshore airflow. The short-duration afternoon precipitation at Yangjiang mainly originates from the precipitation triggered by the mountain located northwest of the station. Zhanjiang shows convergence in the afternoon, and this convergence corresponds well with the afternoon precipitation in this location. In contrast, influenced by the curvature of the coastline and the flat terrain, Zhanjiang lacks dynamic convergence in the morning, which can trigger precipitation, resulting in the absence of morning precipitation events, and this is why Zhanjiang presents less precipitation than the other two stations.

It is also worth noting that the heavy rainfall events over the South China coast are often associated with 
boundary layer jets (Du et al. 2014). Figure 14 shows the diurnal cycle of the occurrence number of $925-\mathrm{hPa}$ strong wind (wind speed greater than $12 \mathrm{~m} \mathrm{~s}^{-1}$ ). There is a strong single peak around 0200 LST at Dongxing, which favors the low-level convergence and the morning heavy precipitation. The frequency of $925-\mathrm{hPa}$ strong wind at Yangjiang presents comparable double peaks (at night and afternoon, respectively), which corresponds to the double peaks of precipitation amount.

This study analyzes the precipitation characteristics over the area to the west of $110^{\circ} \mathrm{E}$ in South China, which is less concerned by the previous studies. In addition, the regional differences in precipitation are presented by comparing the precipitation characteristics from Dongxing to Yangiiang along the coastline. These regional differences in the hourly precipitation characteristics can serve as a new benchmark to evaluate the results of high-resolution numerical models. This study also distinguishes different kinds of precipitation events and analyses the evolution process for different kinds of events associated with the atmospheric circulation. These analyses are helpful for enriching the understanding of the possible influence mechanism of precipitation, especially for the area west of $110^{\circ} \mathrm{E}$ (such as Dongxing). In addition, the reason for the low precipitation amount over the Leizhou Peninsula is also clarified through this kind of analysis. The analysis based on the different precipitation processes can also be used for model evaluation. The sources of biases in the simulated precipitation can be better understood, and the results can provide new insights for model improvements. In view of the complex situation of precipitation over the area east of $110^{\circ} \mathrm{E}$, it is necessary to explore new methods of event identification or more comprehensive diagnosis methods, using high spatial-temporal resolution data (such as radar data) and high-resolution numerical experiments to investigate the detailed mechanisms for triggering and developing precipitation events.

Acknowledgments. This research was supported by the National Natural Science Foundation of China (41675075, 91637210, and 91737306) and the Jiangsu Collaborative Innovation Center for Climate Change.

\section{REFERENCES}

Albergel, C., E. Dutra, S. Munier, J.-C. Calvet, J. Munoz-Sabater, P. de Rosnay, and G. Balsamo, 2018: ERA-5 and ERA-Interim driven ISBA land surface model simulations: Which one performs better? Hydrol. Earth Syst. Sci., 22, 3515-3532, https:// doi.org/10.5194/hess-22-3515-2018.

Augustine, J. A., and K. W. Howard, 1991: Mesoscale convective complexes over the United States during 1986 and 1987.
Mon. Wea. Rev., 119, 1575-1589, https://doi.org/10.1175/15200493(1991)119<1575:MCCOTU>2.0.CO;2.

Baker, R. D., B. H. Lynn, A. Boone, W. Tao, and J. Simpson, 2001: The influence of soil moisture, coastline curvature, and land-breeze circulations on sea-breeze-initiated precipitation. J. Hydrometeor., 2, 193-211, https://doi.org/ 10.1175/1525-7541(2001)002<0193:TIOSMC $>2.0 . C O ; 2$.

Chen, G., W. Sha, and T. Iwasaki, 2009a: Diurnal variation of precipitation over southeastern China: Spatial distribution and its seasonality. J. Geophys. Res., 114, D13103, https:// doi.org/10.1029/2008JD011103.

,-- , and $-2009 \mathrm{~b}$ : Diurnal variation of precipitation over southeastern China: 2. Impact of the diurnal monsoon variability. J. Geophys. Res., 114, D21105, https://doi.org/10.1029/ 2009JD012181.

_ R. Lan, W. Zeng, H. Pan, and W. Li, 2018: Diurnal variations of rainfall in surface and satellite observations at the monsoon coast (South China). J. Climate, 31, 1703-1724, https://doi.org/ 10.1175/JCLI-D-17-0373.1.

Chen, J., Y. Zheng, X. Zhang, and P. Zhu, 2013: Distribution and diurnal variation of warm-season short-duration heavy rainfall in relation to the MCSs in China. Acta Meteor. Sin., 27, 868-888, https://doi.org/10.1007/s13351-013-0605-x.

Chen, X., K. Zhao, and M. Xue, 2014: Spatial and temporal characteristics of warm season convection over Pearl River Delta region, China, based on 3 years of operational radar data. J. Geophys. Res., 119, 12 447-12 465, https://doi.org/10.1002/ 2014JD021965.

,,--- , B. Zhou, X. Huang, and W. Xu, 2015: Radarobserved diurnal cycle and propagation of convection over the Pearl River Delta during Mei-Yu season. J. Geophys. Res. Atmos., 120, 12 557-12 575, https://doi.org/10.1002/ 2015JD023872.

_ F. Zhang, and K. Zhao, 2016: Diurnal variations of the landsea breeze and its related precipitation over South China. J. Atmos. Sci., 73, 4793-4815, https://doi.org/10.1175/JAS-D16-0106.1.

, - _ , and J. H. Ruppert Jr., 2019: Modulations of the diurnal cycle of coastal rainfall over South China caused by the boreal summer intraseasonal oscillation. J. Climate, 32, 2089-2108, https://doi.org/10.1175/JCLI-D-18-0786.1.

Du, Y., and R. Rotunno, 2018: Diurnal cycle of rainfall and winds near the south coast of China. J. Atmos. Sci., 75, 2065-2082, https://doi.org/10.1175/JAS-D-17-0397.1.

—, Q. Zhang, Y. Chen, Y. Zhao, and X. Wang, 2014: Numerical simulations of spatial distributions and diurnal variations of low-level jets in China during early summer. J. Climate, 27, 5747-5767, https://doi.org/10.1175/JCLI-D-13-00571.1.

Hersbach, H., and D. Dee, 2016: ERA5 reanalysis is in production. ECMWF Newsletter, No. 147, ECMWF, Reading, United Kingdom, https://www.ecmwf.int/en/newsletter/ 147/news/era5-reanalysis-production.

Houze, R. A., Jr., B. F. Smull, and P. Dodge, 1990: Mesoscale organization of springtime rainstorms in Oklahoma. Mon. Wea. Rev., 118, 613-654, https://doi.org/10.1175/1520-0493(1990) 118<0613:MOOSRI $>2.0 . \mathrm{CO} ; 2$.

Huang, W. R., J. C. L. Chan, and A. Y. M. Au-Yeung, 2013: Regional climate simulations of summer diurnal rainfall variations over East Asia and Southeast China. Climate Dyn., 40, 1625-1642, https://doi.org/10.1007/s00382-012-1457-2.

Jiang, Z., D. L. Zhang, R. Xia, and T. Qian, 2017: Diurnal variations of presummer rainfall over southern China. J. Climate, 30, 755-773, https://doi.org/10.1175/JCLI-D-15-0666.1. 
Joyce, R. J., J. E. Janowiak, P. A. Arkin, and P. Xie, 2004: CMORPH: A method that produces global precipitation estimates from passive microwave and infrared data at high spatial and temporal resolution. J. Hydrometeor., 5, 487-503, https://doi.org/ 10.1175/1525-7541(2004)005<0487:CAMTPG >2.0.CO;2.

Li, J., and R. Yu, 2014: A method to linearly evaluate rainfall frequency-intensity distribution. J. Appl. Meteor. Climatol., 53, 928-934, https://doi.org/10.1175/JAMC-D-13-0272.1.

— _ - and T. Zhou, 2008: Seasonal variation of the diurnal cycle of rainfall in southern contiguous China. J. Climate, 21, 6036-6043, https://doi.org/10.1175/2008JCLI2188.1.

Li, X., N. C. Lau, and T. C. Lee, 2018: An observational study of the diurnal variation of precipitation over Hong Kong and the underlying processes. J. Appl. Meteor. Climatol., 57, 13851402, https://doi.org/10.1175/JAMC-D-17-0320.1.

Luo, Y., H. Wang, R. Zhang, W. Qian, and Z. Luo, 2013: Comparison of rainfall characteristics and convective properties of monsoon precipitation systems over South China and the Yangtze and Huai River Basin. J. Climate, 26, 110-132, https:// doi.org/10.1175/JCLI-D-12-00100.1.

_ , and Coauthors, 2017: The Southern China Monsoon Rainfall Experiment (SCMREX). Bull. Amer. Meteor. Soc., 98, 9991013, https://doi.org/10.1175/BAMS-D-15-00235.1.

Ma, Y., X. Wang, and Z. Y. Tao, 1997: Geographic distribution and life cycle of mesoscale convective system in China and its vicinity. Prog. Nat. Sci., 7, 583-589.

Neumann, J., 1951: Land breezes and nocturnal thunderstorms. J. Meteor., 8, 60-67, https://doi.org/10.1175/1520-0469(1951) 008<0060:LBANT $>2.0$.CO;2.

Satoh, M., and Y. Kitao, 2013: Numerical examination of the diurnal variation of summer precipitation over southern China. SOLA, 9, 129-133, https://doi.org/10.2151/sola.2013-029.

Shen, Y., P. Zhao, Y. Pan, and J. Yu, 2014: A high spatiotemporal gauge-satellite merged precipitation analysis over China. J. Geophys. Res. Atmos., 119, 3063-3075, https://doi.org/ 10.1002/2013JD020686.

Wang, H., Y. Luo, and B. J. D. Jou, 2014: Initiation, maintenance, and properties of convection in an extreme rainfall event during SCMREX: Observational analysis. J. Geophys. Res., 119, 13 206-13 232, https://doi.org/10.1002/2014JD022339.

Wang, Y., and L. Zhou, 2005: Observed trends in extreme precipitation events in China during 1961-2001 and the associated changes in large-scale circulation. Geophys. Res. Lett., 32, L09707, https://doi.org/10.1029/2005GL023769.

Wu, M., and Y. Luo, 2016: Mesoscale observational analysis of lifting mechanism of a warm-sector convective system producing the maximal daily precipitation in China mainland during pre-summer rainy season of 2015. J. Meteor. Res., 30, 719-736, https://doi.org/10.1007/s13351-016-6089-8.

Wu, Y., S. Y. Wu, J. Wen, M. Xu, and J. Tan, 2016: Changing characteristics of precipitation in China during 1960-2012. Int. J. Climatol., 36, 1387-1402, https://doi.org/10.1002/joc.4432.

$\mathrm{Xu}$, W., 2013: Precipitation and convective characteristics of summer deep convection over East Asia observed by TRMM. Mon. Wea. Rev., 141, 1577-1592, https://doi.org/10.1175/ MWR-D-12-00177.1.

- E. J. Zipser, and C. Liu, 2009: Rainfall characteristics and convective properties of mei-yu precipitation systems over South China, Taiwan, and the South China Sea. Part I: TRMM observations. Mon. Wea. Rev., 137, 4261-4275, https://doi.org/ 10.1175/2009MWR2982.1.

Yang, X., J. Fei, X. Huang, X. Cheng, L. M. Carvalho, and H. He, 2015: Characteristics of mesoscale convective systems over China and its vicinity using geostationary satellite FY2. J. Climate, 28, 4890-4907, https://doi.org/10.1175/JCLI-D-1400491.1

Yu, R., Y. Xu, T. Zhou, and J. Li, 2007: Relation between rainfall duration and diurnal variation in the warm season precipitation over central eastern China. Geophys. Res. Lett., 34, L13703, https://doi.org/10.1029/2007GL030315.

Yuan, W., R. Yu, M. Zhang, W. Lin, H. Chen, and J. Li, 2012a: Regimes of diurnal variation of summer rainfall over subtropical East Asia. J. Climate, 25, 3307-3320, https://doi.org/ 10.1175/JCLI-D-11-00288.1.

_ J. Li, H. Chen, and R. Yu, 2012b: Intercomparison of summer rainfall diurnal features between station rain gauge data and TRMM 3B42 product over central eastern China. Int. J. Climatol., 32, 1690-1696, https://doi.org/10.1002/joc.2384.

Zhai, P., X. Zhang, H. Wan, and X. Pan, 2005: Trends in total precipitation and frequency of daily precipitation extremes over China. J. Climate, 18, 1096-1108, https://doi.org/10.1175/ JCLI-3318.1.

Zhang, Q., Y. Zhao, and S. Fan, 2016: Development of hourly precipitation datasets for national meteorological stations in China (in Chinese). Torrential Rain Disasters, 35, 182-186, https://doi.org/10.3969/j.issn.1004-9045.2016.02.011.

Zhao, Y., X. Zou, L. Cao, and X. Xu, 2014: Changes in precipitation extremes over the Pearl River Basin, southern China, during 1960-2012. Quat. Int., 333, 26-39, https://doi.org/ 10.1016/j.quaint.2014.03.060.

Zheng, Y. G., and J. Chen, 2013: A climatology of deep convection over South China and the adjacent waters during summer. J. Trop. Meteor., 19, 1-15.

- - — , and P. J. Zhu, 2008: Climatological distribution and diurnal variation of mesoscale convective systems over China and its vicinity during summer. Chin. Sci. Bull., 53, 1574-1586, https://doi.org/10.1007/s11434-008-0116-9.

—, M. Xue, B. Li, J. Chen, and Z. Tao, 2016: Spatial characteristics of extreme rainfall over China with hourly through 24-hour accumulation periods based on national-level hourly rain gauge data. Adv. Atmos. Sci., 33, 1218-1232, https:// doi.org/10.1007/s00376-016-6128-5.

_, Y. Gong, J. Chen, and F. Tian, 2019: Warm-season diurnal variations of total, stratiform, convective, and extreme hourly precipitation over central and eastern China. $A d v$. Atmos. Sci., 36, 143-159, https://doi.org/10.1007/s00376018-7307-3.

Zhou, T., R. Yu, H. Chen, A. Dai, and Y. Pan, 2008: Summer precipitation frequency, intensity, and diurnal cycle over China: A comparison of satellite data with rain gauge observations. J. Climate, 21, 3997-4010, https://doi.org/10.1175/ 2008JCLI2028.1.

Zhu, L., Z. Meng, F. Zhang, and P. M. Markowski, 2017: The influence of sea- and land-breeze circulations on the diurnal variability in precipitation over a tropical island. Atmos. Chem. Phys., 17, 13 213-13 232, https://doi.org/10.5194/acp-1713213-2017. 